\title{
O desejo de partir: um estudo a respeito da tentativa de suicídio
}

The desire to leave: a study about attempted suicide

El deseo de partir: un estudio sobre intentos de suicidio

\author{
Giovana Vidotto Roman Toro* \\ Nely Aparecida Guernelli Nucci* \\ Tatiana Bruno de Toledo ${ }^{* * *}$ \\ Andréia Elisa Garcia de Oliveira ${ }^{* * * *}$ \\ Helena Bazanelli Prebianchi $i^{* * * *}$
}

\begin{abstract}
Resumo
O objetivo deste trabalho foi refletir, à luz de uma revisão de literatura, sobre a experiência vivenciada no atendimento psicológico aos pacientes internados em um hospital-geral por tentativa de suicídio, dentro do Programa de Residência em Saúde, área Psicologia Hospitalar. Não foi apresentado nenhum caso em específico, tampouco os pacientes foram abordados como participantes deste estudo. A experiência da autora serviu como pano de fundo para tais reflexóes, assim como pode ser considerada como um elemento motivador para a realização de uma pesquisa bibliográfica sobre o tema em questão. As considerações apontaram para a relevância da discussão do tema entre a equipe, visando a um atendimento integrado, uma atenção global ao paciente e à prevenção de novas tentativas de suicídio.
\end{abstract}

Palavras-chave: Tentativa de suicídio. Hospital-geral. Assistência psicológica. Equipe multidisciplinar.

\footnotetext{
Especialista em Psicologia da Saúde pelo Hospital e Maternidade Celso Pierro - PUC Campinas, graduada em Psicologia pela Universidade Federal de Uberlândia, psicóloga hospitalar na Santa Casa de Misericórdia de São Paulo. E-mail: giovanatoro@gmail.com.

** Doutora em Psicologia pela Universidade de São Paulo, mestra e graduada em Psicologia pela Pontifícia Universidade Católica de Campinas (PUC Campinas), psicóloga do Centro de Oncologia do Hospital Municipal Dr. Mário Gatti, em Campinas-SP. E-mail: nnucci@terra.com.br.

*** Especialista em Psicologia da Saúde pelo Hospital e Maternidade Celso Pierro - PUC Campinas, graduada em Psicologia pela PUC Campinas, psicóloga hospitalar no Hospital Municipal Dr. José de Carvalho Florence, em São José dos CamposSP. E-mail: tati_toledo10@yahoo.com.br.

**** Doutoranda em Psicologia pela PUC-Campinas, mestra pela mesma instituição, especialista em Psicologia da Saúde pelo Hospital e Maternidade Celso Pierro - PUC Campinas, graduada em Psicologia pela Universidade Paulista (Unip Campinas). E-mail: andreiaegarcia@yahoo.com.br.

${ }^{* * * * *}$ Doutora em Psicologia Profissão e Ciência pela PUC Campinas, mestra e graduada em Psicologia pela mesma instituição. E-mail: helenabp@puc-campinas.edu.br.
} 


\section{Abstract}

The objective of this study was to reflect, based upon a review of the available literature, upon the experience obtained while carrying out psychological treatment of patients hospitalized because of attempted suicide during a Residency in a Psychology Hospital. No specific cases were discussed, nor were the patients approached as participants in this study. The author's experience served as a backdrop for such reflections, which can be seen as a motivating factor for conducting a review of literature on the topic in question. The considerations pointed to the relevance of the topic of discussion among the team seeking an integrated service, global attention to the patient and the prevention of further suicide attempts.

Keywords: Attempted suicide. Clinical hospital. Pyschological treatment. Multidisciplinary team.

\section{Resumen}

El objetivo de este estudio fue el de reflexionar, partiendo de una revisión de la literatura existente, sobre la experiencia vivida durante las consultas psicológicas con los pacientes internados en un hospital general por intento de suicidio a través del Programa de Residencia en Salud área: Psicología Hospitalaria. No se trató ningún caso en concreto, ni fueron abordados los pacientes como participantes en este estudio. La experiencia del autor sirvió como telón de fondo de estas reflexiones, y se puede considerar como factor motivador para la realización de una revisión de la bibliografía sobre el tema en cuestión. Las consideraciones indicaron la relevancia del estudio del tema entre el equipo, buscando un servicio integrado, atención global al paciente y prevención de nuevos intentos de suicidio.

Palabras clave: Intento de suicidio. Hospital general. Asistencia psicológica. Equipo muldisciplinar.

0 suicídio é um tema instigante que trazà tona diversas reflexões a respeito da vida e da morte. Pensar em motivações, compreender psicologicamente as razóes pelas quais o indivíduo realiza esse ato contra a sua própria vida é o que estimulou e originou este trabalho. Interesse despertado por meio da experiência adquirida como residente de Psicologia hospitalar, já que a prática proporcionou o contato com pacientes internados por razão de tentativa de suicídio e instigou a busca da compreensão aprofundada sobre o tema. 
Além da experiência prática como psicólogo hospitalar, estudos demonstram a relevância social do tema. A Organização Mundial de Saúde (World Health Organization, 2012) considera o suicídio um problema de saúde pública, visto que dados apontam que uma média de quase um milhão de pessoas se suicida a cada ano. Além disso, durante os últimos 45 anos, as taxas mundiais de suicídio aumentaram $60 \%$; crescimento alarmante que estimula a reflexão do assunto e a criação de um Dia Mundial de Prevenção ao Suicídio, no dia 10 de setembro (World Health Organization, 2012).

Para a sociedade brasileira, o tema também é considerado de extrema importância, demandando, por meio do Ministério da Saúde, o desenvolvimento de uma estratégia nacional para a prevenção do suicídio, que visa a reduzir as taxas de suicídio e os danos associados ao comportamento suicida em nossa população.

Portanto a realização deste estudo objetivou a reflexão, à luz de uma revisão de literatura, sobre a experiência no atendimento psicológico a pacientes internados em um hospital-geral por tentativa de suicídio.

\section{Suicídio: breve histórico}

A palavra suicídio deriva do latim, sui (si mesmo) e caederes (ação de matar), sendo utilizada pela primeira vez em 1737 pelo abade Desfointaines. Essa palavra foi incorporada posteriormente pela comunidade científica no século XIX, buscando-se explicações psiquiátricas e sociológicas para o tema (Moron, 1987).

Segundo Venco e Barreto (2010), a visão do suicídio ganhou novas concepções ao longo dos anos. Desde a Grécia Antiga, já era um tema discutido, sendo considerado como morte voluntária e não como um ato condenável caso existissem boas razões para executá-lo. Kalina e Kovadloff citados por Kovács (1992, p. 169), afirmam que, na Antiguidade grecoromana, "os suicidas não tinham direito a uma sepultura regular, e suas mãos eram enterradas separadamente".

Já na Europa, no século XVII, o ato era considerado um crime e, se a tentativa de suicídio falhasse, o sobrevivente poderia ser encarcerado (Venco \& Barreto, 2010).

Discussões sobre a aceitação do ato do suicídio são recorrentes em diferentes períodos e sociedades, e estão diretamente interligadas à cultura, à visão moral, o que dificulta um consenso geral. Atualmente, o suicídio se insere no campo dos transtornos mentais, é um tema relacionado a psicopatologias, 
investigam-se suas verdadeiras causas e a prevenção, associando-as a fatores biológicos e psicológicos (Venco \& Barreto, 2010).

Segundo Cassorla (1991, p. 20), "Não existe uma causa para o suicídio. Trata-se de um evento que ocorre como culminância de uma série de fatores que vão se acumulando na biografia do indivíduo". A história do suicídio ganha vozes múltiplas e diversas explicações de ordem psicológica, sociológica, filosófica e, ou, biológica, multiplicidade que confere ao fenômeno a devida complexidade.

\section{Afinal, o que motiva o ser humano a dar um fim à sua própria vida?}

A Sociologia é uma das áreas do conhecimento que procuram estudar e explicar o suicídio. Diante de vários estudiosos que contribuíram para o aprofundamento do tema, encontra-se Émile Durkheim (1858-1917), sociólogo francês que destinou parte de seus escritos à questão.

Durkheim publicou, em 1897, o livro intitulado "Le Suicide" (O suicídio), defendendo que as causas do autoextermínio têm fundamento social e não individual. Sendo o suicídio definido como "todo caso de morte que resulte direta ou indiretamente de um ato positivo ou negativo, praticado pela própria vítima, sabedora de que devia produzir esse resultado" (Durkheim, 1982, p. 16).

Em seus estudos, o sociólogo classifica o suicídio em três tipos: egoísta, altruísta e anômico. O primeiro tipo, o suicídio egoísta, tem como causas a depressão, a melancolia, a sensação de desamparo moral, provocados pela desintegração social.

O segundo tipo de suicídio é chamado de altruísta, e ocorre com mais frequência nas sociedades primitivas, em que é percebido como um dever que, se não for cumprido, o indivíduo é punido pela desonra e por castigos religiosos. Geralmente ocorre entre as pessoas que chegaram ao limiar da velhice ou adoeceram, entre mulheres por ocasião da morte do marido ou entre fiéis e servidores com o falecimento dos seus chefes. É visto como uma obrigação que a sociedade impõe ao indivíduo (Durkheim, 1982).

O terceiro tipo de suicídio é chamado de anômico. Ocorre devido a um desregramento social, no qual as normas não existem ou perderam o respeito. Acontece quando existe um estado de anomia, em que falta uma orientação, falta uma moral, as relações são precárias e as regras são indefinidas (Durkheim, 1982). 
Durkheim, em sua obra, traz reflexões a respeito da grande influência que a sociedade exerce nos indivíduos, mesmo quando a questão tratada se refere a uma questão individual, que é a escolha ou não da vida, a decisão e opção pelo término, pelo fim da vida, a morte.

A Filosofia é outro ramo do conhecimento que também indaga e reflete sobre o tema. Escritores como Camus, Nieztche, Schopenhauer, entre outros, escreveram a respeito do suicídio. Albert Camus, em "O mito de Sísifo", afirma: "Só existe um problema filosófico realmente sério: o suicídio" (Camus, 1942, p. 7), demonstrando a pertinência do tema, abordado e estudado por diversos filósofos.

Para a Psicologia, o suicídio pode ser compreendido como resultado de uma intensa dor psíquica, um ato inserido no campo da psicopatologia. A palavra patologia derivada do grego pathos, que significa "sofrimento", mas também se relaciona às palavras "paixão" e "passividade" (Macedo \& Werlang, 2007). Desse modo, uma tentativa de suicídio pode ser compreendida e pensada com base nessa mescla de palavras: sofrimento, paixão, passividade, sendo extremamente fundamental considerar a singularidade do ato e seus efeitos no psiquismo.

Ao analisar o suicídio sob a ótica da psicopatologia, esse pode ser considerado como uma saída para uma crise, para um intenso sofrimento, em que sentimentos ambivalentes, de desamparo estão presentes na vida do sujeito.

Reflexões acerca do perfil epidemiológico do paciente que cometeu uma tentativa de suicídio são realizadas por Kovács (1992). A autora reflete sobre dados evidenciados em estudos que associam altas taxas de suicídio à velhice, momento da vida em que o sujeito passa por situaçóes desvitalizantes, em que existem perdas, isolamento social, desemprego. Destaca também a hipótese explicativa para o fato de os homens cometerem mais suicídio do que as mulheres: eles têm menor nível de tolerância à frustração.

Sadock e Sadock (2007) afirmam que alguns fatores de risco e índices devem ser considerados: idade, sexo (gênero), estado civil, emprego, relacionamento interpessoal, antecedentes familiares e saúde (física e familiar). O perfil demográfico e social demonstra alguns fatores de maior risco: pessoas com mais de 45 anos; homens; divorciado ou viúvo; desempregado; com relacionamentos interpessoais e antecedentes familiares conflitantes. Em relação à saúde física, doenças crônicas são consideradas um fator de maior risco, enquanto depressão, transtorno da personalidade grave, abuso de substância, psicose e desesperança são riscos relacionados à saúde mental. 
Segundo os autores, os Estados Unidos é o país em que o suicídio é considerado a oitava causa global de morte.

Lovisi, Santos, Legay, Abelha \& Valencia, (2009) traçam o perfil epidemiológico do suicídio no Brasil entre 1980 e 2006. Afirmam que a taxa de suicídio aumentou 29,5\% em 26 anos. Entretanto afirmam que esse índice nacional é considerado baixo se comparado aos mundiais. Relatam também que a estatística é maior entre indivíduos mais velhos do que entre jovens, todavia essa tendência vem se alterando a partir de 1990, em que há o crescimento do índice na faixa etária dos 20 aos 59 anos.

Botega (2010), em seus estudos sobre o comportamento suicida no Brasil, refere que o País está entre os dez que registram os maiores números absolutos de suicídio e relata que há uma estimativa de que as tentativas de suicídio superem o número de suicídio em pelo menos dez vezes, considerando, portanto, a assistência prestada ao paciente que realizou uma tentativa de suicídio como uma estratégia fundamental para a prevenção.

Estudos apontam mudança no perfil epidemiológico do suicídio. $\mathrm{O}$ aumento da taxa de suicídio contribui para o aumento na taxa de hospitalização das pessoas que tentaram se suicidar.

\section{Tentativa de suicídio, hospitalização, e agora?}

Com a chegada do paciente que cometeu uma tentativa de suicídio ao hospital-geral, ocorre a solicitação de atendimento do médico psiquiatra e do psicólogo hospitalar, profissionais da saúde mental que avaliam o paciente e o acompanham durante a internação.

Ao psicólogo hospitalar cabe a tarefa da escuta, da compreensão, do acolhimento com o objetivo de auxiliar o sujeito nesse caminho, nessa trajetória durante o processo de internação, de adoecimento. Calvett, Silva e Gauer (2008) afirmam que o psicólogo hospitalar é um profissional que deve ser facilitador do fluxo de emoções, reflexões, e que o verdadeiro trabalho terapêutico visa a zelar pela atenção global ao paciente.

A Psicologia da saúde no ambiente hospitalar busca, portanto, compreender os aspectos psíquicos e psicossociais do ser humano, com o objetivo prestar a assistência ao paciente, podendo contribuir também para uma melhor relação profissional-paciente e ambiente humanizados.

O profissional da saúde mental deve oferecer ao sujeito um espaço de escuta em que ele possa falar sobre a morte, sem precisar negar essa pulsão. O psicólogo "deve propor e sustentar a terapia como um espaço para se 
reimaginar a morte e o corpo [...], de maneira que o paciente possa trazer livremente suas fantasias e ideias" (Oliveira, 2012, p. 106). Segundo Macedo e Werlang,

A escuta do ato da tentativa de suicídio pode ajudar o sujeito a criar e/ou desenvolver sua potencialidade simbólica. Portanto, parte-se do pressuposto de que o que é descarregado no ato de tentar acabar com a própria vida tem íntima relação com um excesso derivado de vivências traumáticas às quais não foi possível dar uma atribuição de sentido ou obter uma captura no mundo representacional do sujeito. (Macedo e Werlang, 2007, p. 87).

A escuta da vivência única e singular se delineia como fundamental para o entendimento da tentativa de suicídio e para o auxílio ao indivíduo. $\mathrm{O}$ suicídio é um ato que tem como finalidade encontrar uma solução para um sofrimento intenso e é marcado por uma atitude interna ambivalente, pois, ao mesmo tempo em que o indivíduo quer alcançar a morte, ele busca ajuda, socorro (Werlang, Macedo \& Kruger, 2004). Um pedido de ajuda realizado no momento em que o indivíduo não encontra mais sentido para sua vida, em que o vazio existencial permeia sua alma.

Segundo Frankl (2008), a depressão, agressão e vício são comportamentos subjacentes ao vazio existencial, e a busca de sentido da vida varia de pessoa para pessoa, de momento para momento e, portanto, somente a pessoa pode responder qual o sentido da vida para ela. Ela se torna responsável por suas escolhas e por esse processo de autoconhecimento.

\section{A prática no hospital: pedidos de ajuda, histórias reais}

Durante a prática como residente de Psicologia hospitalar, a assistência psicológica foi prestada a diferentes pacientes internados por tentativa de suicídio. Cada um deles revelou uma história singular, única, um sofrimento existencial com significados e significantes pessoais, particulares e paradoxalmente compreensíveis e incompreendidos.

Os atendimentos ocorreram no pronto-socorro, na unidade de terapia intensiva e nas enfermarias de um hospital-geral universitário ligado a uma instituição privada de ensino, localizado no interior do Estado de São Paulo, que realiza atendimentos com subsídios do SUS, bem como convênios e particulares. A avaliação do serviço de Psicologia era solicitada 
pelas equipes de enfermagem e, ou, médica, que identificavam a demanda psicológica trazida por esses pacientes.

\section{O paciente e suas motivações: a teoria anunciada na realidade}

Ao ser solicitado o atendimento psicológico ao paciente, uma avaliação inicial era realizada e havia o acompanhamento durante o período de internação. Os atendimentos apontaram para dados relevantes, com a prevalência de atendimentos a homens, relacionamentos interpessoais e antecedentes familiares conflitantes, entendidos como fatores que aumentam o risco da ocorrência do comportamento suicida elucidados na teoria por Sadock e Sadock (2007).

Outros fatores de risco apontados por Bertolote, Mello-Santos e Botega (2010) também apareceram na prática. Os autores referem que a presença de histórico de suicídio e de doença psiquiátrica na família assim como os transtornos mentais prévios elevam o risco da tentativa de suicídio. Entre os transtornos mentais desencadeantes mais comuns entre os pacientes com comportamento suicida, destacam-se a presença do transtorno de humor (principalmente a depressão) seguida pelos transtornos por uso de substância (álcool) e esquizofrenia.

Os autores afirmam que "a tentativa de suicídio tem as mesmas características fenomenológicas do suicídio, diferindo deste apenas quanto ao desfecho, que não é fatal" (Bertolote, Mello-Santos \& Botega, 2010, p. 88).

Apesar de não ter tido um desfecho fatal para o paciente, observou-se, por meio dos atendimentos, que a tentativa de suicídio deixa marcas profundas na subjetividade. Foram encontrados seres humanos fragilizados, em que o sofrimento existencial e as angústias emergiram, sendo que eles se viam mergulhados em sentimentos ambivalentes: revolta, arrependimento, alívio, culpa, entre outros.

Ao refletir sobre os atendimentos psicológicos realizados, foi possível relembrar alguns exemplos de pedidos realizados pelas equipes médica e, ou, de enfermagem.

O pronto-socorro pode ser considerado um dos locais de maior movimentação, agitação do hospital, e desse setor surgiram diversas solicitações de atendimentos do serviço de Psicologia.

Um dos pedidos realizados pela equipe de enfermagem foi a um paciente adulto, do sexo masculino, que cometeu tentativa de suicídio em seu próprio ambiente de trabalho por meio de uma tentativa de enforcamento. A psicóloga abordou o paciente, que estava deitado em uma maca e já havia sido avaliado 
pelo serviço de psiquiatria. Ele se mostrou receptivo, expressou sentimentos de arrependimento, culpa e preocupaçôes. Relatou histórico familiar prévio de suicídio: seu pai havia cometido suicídio quando o paciente era adolescente e agora ele se recordava de sua história, verbalizava sobre o motivo pelo qual havia chegado até o hospital.

Observou-se, por meio do único atendimento psicológico ocorrido, que o paciente demonstrava desejo de ajuda, sentia-se envergonhado, não sabia como lidar com a situação e como seria sua vida a partir do momento atual, como sua família reagiria.

Ainda no pronto-socorro, outro atendimento pôde ser destacado, de um pedido realizado pela equipe médica. Uma paciente adulta, do sexo feminino, que havia cometido sua terceira tentativa suicídio pela ingestão de medicamentos. Durante os três atendimentos realizados pela psicóloga, a paciente apresentava uma postura apática, um olhar distante, relatava alguns fatos de sua vida e afirmava sentir um "vazio".

Além do pronto-socorro, outros setores também solicitavam a avaliação psicológica dos pacientes. Em um atendimento psicológico ocorrido na enfermaria, o paciente, do sexo masculino, em idade adulta, foi receptivo ao acompanhamento psicológico durante a internação. $\mathrm{O}$ paciente verbalizava sentimentos intensos de revolta diante da tentativa frustrada de suicídio, julgando-se incapaz e incompetente até mesmo para "dar fim à sua vida", apresentava raiva diante da situação atual.

Foi possível perceber um fator comum aos pacientes atendidos: o sofrimento existencial, que direcionou o trabalho terapêutico por meio de uma escuta compreensiva, de um cuidado e abriu uma oportunidade de ressignificação de sua história pessoal. À psicóloga coube proporcionar um espaço de acolhimento a esses pacientes, para que eles pudessem, por meio da fala, do simbólico, elaborar o ocorrido e identificar novas vivências possíveis. Foi oferecido o apoio psicológico durante aquele momento imediato de emergência e ao longo de todo o período de internação, com o objetivo de auxiliar o indivíduo nesse momento de crise de sua vida e contribuir com a prevenção de novas tentativas de suicídio.

\section{A equipe e o pedido de ajuda}

Notou-se, na instituição, que o pedido de ajuda ocorreu, primeiramente, por parte da própria equipe de saúde que, muitas vezes, enfrentava dificuldades em lidar com o paciente e com a situação em especial. 
Ao retornar à teoria, estudos apontam diferentes posturas dos profissionais da saúde diante desse paciente. Silva e Boemer (2004) relatam que a assistência ao paciente que realizou tentativa de suicídio desperta diversos sentimentos no profissional de saúde (sentimentos de impotência, fragilidade, culpa, frustração, desespero, desprezo agressivo).

Durante a prática no hospital, por meio da discussão de caso com a equipe que solicitava o atendimento psicológico, foi possível trabalhar alguns desses sentimentos da equipe.

A impotência foi percebida em um pedido do médico psiquiatra, que solicitou atendimento psicológico ao paciente que havia cometido a terceira tentativa de suicídio durante o mesmo mês. A assistência multidisciplinar, envolvendo a atenção à saúde mental, não impediu a reincidência nessas tentativas de pôr fim à vida, trazendo ao profissional sentimentos de impotência e frustração por não conseguir eliminar esse "desejo de partir", por não poder livrar o paciente da dor psíquica intensa que o consumia a ponto de não encontrar um sentido em sua existência.

A raiva foi outro sentimento que se revelou, por meio da prática no hospital, nas equipes de enfermagem e médica. Raiva diante do indivíduo que acelera/deseja o processo de morte, contrariando justamente o trabalho do profissional de saúde: salvar, preservar vidas.

O acolhimento, a escuta e a valorização do que foi percebido por esses profissionais fez parte da intervenção psicológica, que visou a oferecer um espaço de escuta não somente ao paciente, mas também aos profissionais. Por meio dessa escuta ao profissional, a psicóloga propiciou uma oportunidade de ele nomear esse sentimento de impotência, tornando-se, inclusive, mais consciente dos sentimentos que acompanham essa sensação, como a raiva, por exemplo. Ao se apropriar do incômodo que sente em se dedicar ao cuidado de uma pessoa que insiste em deixar a vida, negligenciando os esforços da equipe para salvá-la, o profissional pôde ressignificar essa experiência de um modo que não lhe soasse apenas como uma perda de tempo, mas como uma peculiaridade da população atendida devido ao estado de vulnerabilidade psíquica em que se encontra. Assim, o profissional teve a oportunidade de compreender as múltiplas tentativas pelo viés do paciente e não apenas pelo seu próprio olhar, desenvolvendo uma postura mais empática.

Outros aspectos importantes relacionados à postura de intervenção são citados na teoria por Bertolote, Mello-Santos e Botega (2010), que relatam as posturas adequadas dos profissionais de saúde diante do comportamento suicida. Afirmam que devem ser capazes de "identificar o risco, proteger o 
paciente e remover ou tratar os fatores de risco" (Bertolote, Mello-Santos \& Botega, 2010, p. 90).

$\mathrm{Na}$ instituição onde foi realizada a prática, o cuidado na assistência aos pacientes envolve a identificação de possíveis riscos clínicos, emocionais e, ou, sociais, por meio de um protocolo de avaliação multidisciplinar que é aplicado a todos os pacientes, independente das causas da internação. Entretanto, destaca-se que não existe um protocolo institucional que investigue especificamente os riscos de tentativa de suicídio, que contemple aspectos importantes a serem avaliados, tais como presença de transtorno psiquiátrico prévio, ideação de suicida, tentativa de suicídio prévia, situações conflitantes/estressoras, entre outros.

Ao psicólogo hospitalar, portanto, é fundamental compreender a dinâmica institucional e da equipe de saúde, a fim de promover maior atenção e se comprometer com uma prática engajada e contextualizada.

\section{Reflexões acerca da assistência psicológica}

O trabalho da psicóloga foi iniciado por meio de uma primeira avaliação psicológica, e o acompanhamento aos pacientes se deu durante o período de internação. Ressalta-se que, oficialmente, a atenção psicológica era direcionada exclusivamente aos pacientes devido ao excesso de demanda e à escassez de profissionais para oferecer um suporte concomitante à equipe de saúde. No entanto, o que ocorria informalmente era que a própria equipe dava indícios de que estava demandando essa atenção e, sempre que possível, esta era realizada pelo mesmo profissional que estava acompanhando o paciente.

Durante a assistência, foi percebido que o acompanhamento psicológico ao paciente, na maioria das vezes, durou um curto tempo, dois ou três encontros, decorrente da média do tempo de internação do paciente ser de quatro dias. Esse fato traz à tona o seguinte questionamento: a prática nesses atendimentos pôde ser considerada uma modalidade de plantão psicológico, devido à brevidade do acompanhamento psicológico e pelo mesmo ser circunscrito à queixa. Essa modalidade de atendimento é considerada como um encontro situacional e ocorre quando há uma questão de emergência, que faz com que o paciente procure a escuta (Morato, 2006).

O Plantão Psicológico é uma prática de atenção psicológica que tem começo, meio e fim, em um único encontro, e teve início no Serviço de Aconselhamento Psicológico do Instituto de Psicologia da Universidade de 
São Paulo, no ano de 1969, sendo implantado pelos profissionais Rachel Rosenberg e Oswaldo de Barros Santos. Por meio de um encontro, busca esclarecer ao cliente a demanda por ele apresentada e favorecer um redirecionamento dos rumos de sua própria existência, havendo a possibilidade do agendamento de retornos ao Plantão, dependendo da demanda e das necessidades do cliente (Morato, 2009).

O Plantão, por meio da escuta compreensiva, acolhe a experiência de sofrimento do cliente no momento em que procura ajuda, ressaltando o entorno sociopsicológico. Visa ao acolhimento, ao cuidado, possibilitando um atendimento imediato ao usuário e, se necessário, realiza encaminhamentos para a rede de apoio social (Barreto, 2009).

Ao refletir sobre a prática exercida pela psicóloga hospitalar, ressaltou-se que a modalidade do Plantão Psicológico foi adequada nesses atendimentos, considerando alguns aspectos: é uma prática em que se trabalha com o paciente uma questão emergencial; o encontro é único, havendo continuidade e retorno se identificada essa necessidade pelo paciente e pelo psicólogo. Além disso, após esses encontros, é considerada a possibilidade e o desejo de continuidade de acompanhamento psicológico, fora da instituição, visando à realização de possíveis encaminhamentos para a rede de saúde de atenção primária.

\section{Encaminhamentos}

A partir do momento em que ocorre a proximidade da alta hospitalar, a psicóloga observa se há a necessidade da realização de encaminhamento à rede de saúde para a continuidade do processo psicoterapêutico.

Alguns dos pacientes atendidos já eram assistidos por psicólogos e, ou, psiquiatras. Quando não identificados esses acompanhamentos prévios, considerou-se o desejo e, ou, interesse do paciente em dar continuidade a esse processo para a realização de encaminhamentos à rede de saúde, sendo importante ressaltar que, nos casos atendidos, houve interesse do paciente em ser encaminhado.

O encaminhamento ocorre por meio do contato, via telefone, às unidades básicas de saúde (UBS), para verificar a existência de profissional de Psicologia como também a possibilidade de acompanhamento ao paciente. Quando verificada a impossibilidade nas UBSs, outros contatos públicos da rede são acionados, como ambulatórios de Psicologia e, ou, clínicas-escola. 


\section{Considerações finais}

A experiência por meio da prática profissional, durante os atendimentos psicológicos a pacientes internados em razão de ter cometido tentativa de suicídio, permitiu diversas reflexôes sobre o tema.

Diante das evidências da literatura e das vivências, torna-se imprescindível ressaltar que ao psicólogo cabe um importante trabalho a ser realizado em atendimentos de tentativas de suicídio, envolvendo intervenção não só ao paciente como também à equipe multidisciplinar e aos familiares.

A implantação de um protocolo específico para a tentativa de suicídio na instituição é um passo a ser refletido, visto que, no hospital onde a prática ocorreu, existem vários protocolos direcionados à identificação e gerenciamento de potenciais riscos dos pacientes, entretanto nenhum deles é direcionado exclusivamente aos casos de tentativa de suicídio, o que inviabiliza uma compreensão mais global sobre as características desse fenômeno dessa instituição, tais como o perfil da população e o histórico das tentativas prévias.

Esse protocolo deveria abranger alguns aspectos: a coleta de dados da história do indivíduo por meio da entrevista clínica, considerando fatores sociodemográficos, psicológicos e psiquiátricos; analisando fatores preditores de repetição da tentativa de suicídio (tratamento psiquiátrico anterior, transtorno de personalidade, história prévia de hospitalização por autoagressões, entre outros) para a determinação de um tratamento específico para cada paciente (Botega, Rapeli \& Casi, 2006). O envolvimento das equipes médica (clínico-geral, psiquiatra), de enfermagem, de psicologia e de serviço social possibilitaria a padronização de condutas dos profissionais de saúde e contribuiria para a prevenção da reincidência desse ato.

A implantação desse protocolo, por meio de um esforço interdisciplinar, seria importante para que as informaçôes por ele coletadas não atendessem apenas à burocratização do serviço, mas que subsidiassem o diálogo entre as equipes na direção de intervenções mais assertivas e, acima de tudo, orientassem a tomada de decisões.

A tentativa de suicídio é um fenômeno multicausal, que impacta e afeta os indivíduos envolvidos nesse ato. Por isso se reafirma a importância de estudos que visem a compreender melhor essa dinâmica, promovendo a prevenção como também uma melhora na assistência, no cuidado a esses pacientes. 


\section{Referências}

Barreto, C. L. B. T. (2009). Modalidades de prática psicológica clínica atenção psicológica e atitude fenomenológica hermenêutica. IX Simpósio Nacional de Práticas Psicológicas em Instituiçōes: atenção psicológica: fundamentos, pesquisa e prática. Recife: Unicap. Disponível em: http://laclife.wordpress.com/textose-anais-eletronicos.

Bertolote, J. M., Mello-Santos, C. \& Botega, N. J. (2010). Detecção do risco de suicídio nos serviços de emergência psiquiátrica. Revista Brasileira de Psiquiatria, 32 (Supl. 2), S87-S95.

Botega, N. J. (2010). Comportamento suicida em números. Debates Psiquiatria Hoje, 2 (1). Disponível em: http://www.abp.org.br/download/ PSQDebates_7_Janeiro_Fevereiro_light.pdf.

Botega, N. J., Rapeli, C. B. \& Casi, C. F. S. (2006). Comportamento suicida. In N. J. Botega (Ed.). Prática psiquiátrica no hospital geral: interconsulta e emergência. (pp. 430-481). Porto Alegre: Artmed.

Calvett, P. Ü., Silva, L. M. da \& Gauer, G. J. C. (2008). Psicologia da saúde e criança hospitalizada. Psic, 9 (2). Disponível em: http://pepsic.bvsalud.org/ scielo.php?pid=S1676-73142008000200011\&script=sci_arttext.

Camus, A. (1942). O mito de Sísifo. Disponível em: http://www.visionvox. com.br/biblioteca/a/Albert_Camus_-_O_Mito_de_Sífiso.pdf

Cassorla, R. M. S. (1991). Suicídio: estudos brasileiros. Campinas: Papirus.

Durkheim, E. (1982). O suicídio: estudo sociológico. Rio de Janeiro: Zahar.

Frankl, V. E. (2008). Em busca de sentido. Petrópolis: Vozes.

Kovács, M. J. (1992). Morte e desenvolvimento humano. São Paulo: Casa do Psicólogo.

Lovisi, G. M., Santos, S. A., Legay, L., Abelha, L. \& Valencia, E. (2009). Análise epidemiológica do suicídio no Brasil entre 1980 e 2006. Revista Brasileira de Psiquiatria, 31 (Supl. 2), S86-S93. Disponível em: http://www. scielo.br/pdf/rbp/ v31s2/v31s2a07.pdf.

Macedo, M. M. K. \& Werlang, B. S. G. (2007). Trauma, dor e ato: o olhar da psicanálise sobre uma tentativa de suicídio. Ágora, 10 (1). Disponível em: http:// www.scielo.br/scielo.php?pid=s1516-14982007000100006\&script $=$ sci_ arttext. 
Morato, H.T.P. (2006). Pedido, queixa e demanda no plantão psicológico: querer poder ou precisar? Simpósio Nacional de Práticas Psicológicas em Instituição: Psicologia e Políticas Públicas, 6. Vitória: UFES. Disponível em: http://www.usp.br/coseas/COSEASHP/ADM/Psicologo/VIsimposio/ MORATO - Pedido, queixa e demanda.pdf.

Morato, H. T. P (2009). Plantão Psicológico: inventividade e plasticidade. Simpósio Nacional de Práticas Psicológicas em Instituiçôes - Atenção Psicológica: Fundamentos, Pesquisa e Prática, 9. Recife: Unicap. Disponível em: http:// laclife. wordpress.com/textos-e-anaiseletronicos.

Moron, P. (1987). El suicidio. México: Lito Arte.

Oliveira, S. R. de. (2012). O suicídio e os apelos da alma: reflexóes sobre o suicídio na clínica junguiana com pacientes adolescentes. O Mundo da Saúde, 36 (1), 104-112.

Sadock, V. A. \& Sadock, B. J. (2007). Compêndio de psiquiatria: ciência do comportamento e psiquiatria clínica. Porto Alegre: Artmed.

Silva, V. P. da \& Boemer, M. R. (2004). O suicídio em seu mostrar-se a profissionais de saúde. Revista Eletrônica de Enfermagem, 6 (2). Disponível em: http://www. revistas.ufg.br/index.php/fen/article/view/822/951.

Venco, S. \& Barreto, M. (2010). O sentido social do suicídio no trabalho. Revista Espaço Acadêmico, 9 (108), 1-8.

Werlang, B. G., Macedo, M. M. \& Kruger, L. L. (2004). Perspectiva psicológica. In N. Botega \& B. S. G. Werlang (Org.). Comportamento suicida. (pp. 45-58). Porto Alegre: Artmed.

World Health Organization (2012). Mental heatlh: suicide prevention (Supre). Disponível em: http://www.who.int/mental_health/prevention/suicide/ suicide prevent/es/index.html. 